\title{
ESTIGMA, DISCRIMINACIÓN Y ADHERENCIA AL TRATAMIENTO EN NIÑOS CON VIH Y SIDA. UNA PERSPECTIVA BIOÉTICA
}

\author{
Paola Conde Higuera ${ }^{1}$, María Luisa Pimentel Ramírez ${ }^{1}$, Adolfo Díaz Ávila ${ }^{1}$, Tomás Domingo Mora- \\ talla ${ }^{2}$
}

Resumen: Investigación sobre el proceso de estigma y discriminación en nińos con VIH y SIDA, y sus consecuencias en la adherencia al tratamiento desde una perspectiva bioética. Estudio deliberativo-hermenéutico con el uso de la narrativa en cuidadores primarios y en niños. Se aplicó cuestionarios para determinar la presencia de dichas variables y se realizó la interpretación de la información según la teoría de Paul Ricoeur, en tres momentos: respeto y estima de sí, relaciones interpersonales plenas y ética e instituciones justas. Se estudiaron once casos: seis niños y cinco niñas de los cuales solo tres fueron adherentes: dos y una respectivamente, comprobando la hipótesis de la influencia que el estigma y la discriminación ejercen sobre la adherencia al tratamiento; los casos detectados coincidieron con los de no adherencia al tratamiento. Se deliberó acerca de la problemática sugiriendo cursos de acción prudente en los tres niveles mencionados. Se mostró la importancia en el cuidado y la estima de los cuidadores primarios; ya que interviene en el desarrollo y percepción del síndrome en los niños.

Palabras clave: VIH, nińos, estigma, discriminación, adherencia al tratamiento

Stigma, discrimination and adherence to treatment of children with HIV and AIDS. A bioethical perspective

Abstract: This article discloses the results of an research into the process of stigma and discrimination in children with HIV and aids, and the impact they have on adherence from a bioethics perspective. It is a deliberative hermeneutical study using narrative in primary caregivers and children, questionnaires were applied to determine them the presence of these variables. The interpretation of the data was performed according to the theory of Paul Ricoeur, on three occasions: respect and esteem; fulfilling relationships; and ethical and fair institutions. Eleven cases were studied: 6 boys and 5 girls of which only three were adherents: 2 and 1 respectively. Hypothesis was tested for the influence that stigma and discrimination have on adherence to treatment; detected cases coincided with those of non-adherence to treatment. Discussion of the problem was performed suggesting courses prudent action in all three levels. The importance in caring and esteem showed primary caregivers; as it influences the development and perception of the syndrome in children.

Key words: HIV, children, stigma, discrimination, treatment adherence

Estigma, discriminação e aderência ao tratamento em crianças com HIV e AIDS. Uma perspectiva bioética

Resumo: Investigação sobre o processo de estigma e discriminação em crianças com HIV e AIDS, e suas consequências na aderência ao tratamento a partir de uma perspectiva bioética. Estudo deliberativo-hermenêutico com a utilização da narrativa em cuidadores primários e em crianças. Foram aplicados questionários para determinar a presença das referidas variáveis e se realizou a interpretação da informação segundo a teoria de Paul Ricoeur, em três momentos: respeito e autoestima, relações interpessoais plenas e ética e instituiçóes justas. Se estudaram onze casos: seis meninos e cinco meninas, dos quais só três foram aderentes: dois e uma respectivamente, comprovando a hipótese da influência que o estigma e a discriminação exercem sobre a aderência ao tratamento; os casos detectados coincidiram com os de não aderência ao tratamento. Se deliberou acerca da problemática sugerindo cursos de açáo prudente nos três níveis mencionados. Se mostrou a importância no cuidado e na estima dos cuidadores primários, já que intervém no desenvolvimento e percepção da síndrome em crianças.

Palavras-chave: HIV, crianças, estigma, discriminação, aderência ao tratamento

\footnotetext{
${ }^{1}$ Universidad Autónoma del Estado de México, México

Correspondencia: paolaconde85@gmail.com

${ }^{2}$ Universidad Complutense de Madrid, España
} 


\section{Introducción}

El síndrome de inmunodeficiencia adquirida (SIDA) es una enfermedad compleja, tanto en lo biológico como en el ámbito social, cuya prevalencia continúa incrementándose(1); en 2013 el reporte epidemiológico de las Naciones Unidas indicó que existían hasta entonces aproximadamente 35 millones de sujetos infectados en el mundo, de los cuales 3,2 eran menores de 15 años(2). En México, hasta diciembre de 2013, se reportó que 180.000 personas vivían con VIH y 2.200 eran menores de 14 ańos, y se estima que en Latinoamérica viven 35 mil niños con el virus. Es necesario que se mire hacia este grupo de población afectada, vulnerable no solo por la condición de enfermedad sino por el estado de indefensión, por ser menores(3).

Aun cuando se sabe que el VIH es el responsable de la enfermedad, y se han informado los modos de transmisión o contagio, su asociación como enfermedad propia de cierto grupo de personas fuera de la norma social es estímulo de prejuicios y pánico en la sociedad(4).

El estigma y la discriminación asociados al SIDA han dado impulso a la transmisión del VIH y aumentado en gran medida el impacto, desde los inicios de esta epidemia(5). Estas actitudes continúan manifestándose en todos los países y regiones del mundo, lo que crea obstáculos que impiden prevenir nuevos casos, aliviar el impacto de la enfermedad y propiciar asistencia, tratamiento y apoyo adecuados.

El estigma se ha descrito como un proceso dinámico de devaluación que "desacredita significativamente" a un individuo ante los ojos de los demás(6). Dentro de culturas o contextos particulares, ciertos atributos se magnifican y son definidos por los demás como deshonrosos o indignos.

Este pensamiento de estigma en cuanto al SIDA está asociado a la perversión y a un comportamiento inmoral; a estas actitudes y a la incomprensión hay que sumar el temor al contagio y la ignorancia respecto de los mecanismos de transmisión y el temor a la muerte(7). La enfermedad tiene una implicación ética y moral, ya que transgrede la identidad de las personas: intimidad, orienta- ciones o preferencias, relaciones interpersonales, formación, valores y creencias $(8,9)$. Aunque los niños que padecen esta enfermedad no tienen esa connotación social de merecer su estado serológico, el hecho de tener SIDA implica también actitudes prejuiciosas al contacto con ellos.

La discriminación, tal como la define el ONUSIDA (2000) en su protocolo para la identificación de discriminación contra personas que viven con VIH (10), hace referencia a cualquier forma de distinción, exclusión o restricción arbitrarias que afecten a una persona, generalmente pero no exclusivamente, por motivo de una característica personal inherente o por su presunta pertenencia a un grupo concreto (en el caso del VIH y del SIDA, el estado seropositivo, confirmado o sospechado, de una persona), con independencia de que exista o no alguna justificación para tales medidas.

El actuar discriminativo es un proceso que tiende a reforzar connotaciones negativas, que con frecuencia conduce a diversas formas de abuso contra la población infantil con SIDA(11), y es que en la mayoría de los casos a esto se agrega el padecimiento de las implicaciones de tener uno o ambos padres con la enfermedad o finados por ella.

El SIDA también produce alteraciones en el repertorio conductual y de adaptación de los niños que lo padecen, entre otros motivos, por los factores ambientales, como las experiencias traumatizantes (múltiples procedimientos médicos, hospitalizaciones o muerte de familiares)(12), el deficiente estado de salud en general, el rechazo social, la limitación del acceso a la educación formal, la limitación al juego, la actividad física y las actividades cotidianas.

Dichas alteraciones repercuten en la manera de afrontar la enfermedad y el desarrollo de los nińos con SIDA, incluso pueden afectar al apego a las indicaciones médicas, aunado a otros factores como la disponibilidad al tratamiento o la ayuda institucionalizada $(13,14)$.

La adherencia requiere de cambio de hábitos y de estilo de vida, e implica disciplina en cuanto a la toma de medicamentos, fundamental y determinante para el bienestar de quien vive con SIDA. En los niños los responsables del tratamiento son 
los cuidadores primarios, por lo tanto ambos están involucrados en que este se lleve a cabo $(15,16)$.

En cuestiones de bioética enfocadas al SIDA e infancia, es necesario analizar el contexto de la vida y las actitudes en cuanto a los niños que viven con esta enfermedad, valiéndose de la deliberación y sustentándose en la hermenéutica narrativa para profundizar en la reflexión del problema, estudiar los valores que se encuentran en juego y ponderar en la situación; cuáles y cómo deben aplicarse para conseguir que las actitudes inadecuadas ante esta enfermedad no afecten la adherencia a su tratamiento, por el contrario identificar las pautas de acción que lleven al respeto de sí y fomenten una identidad personal que fortalezca el cuidado de la salud personal así como la responsabilidad de las condiciones de vida que se tienen(17).

La hermenéutica ofrece un método de reflexión y análisis desde la interpretación de Paul Ricoeur, quien señala que la línea de exclusión no está solamente trazada entre los sujetos considerados con buena salud y los sujetos discapacitados: atraviesa también la conciencia de cada uno(18).

La existencia del hombre tiene un objetivo o un fin último: vivir la vida en forma tal que, a su término, se pueda decir que valió la pena haberla vivido. La ética de Paul Ricoeur constituye una alternativa para alcanzar la vida plena mediante el disfrute equitativo de las mejores condiciones posibles para desarrollar los potenciales humanos, cuidar de la salud y vivir una vida buena. Esta opción evita que las personas, en cualquier etapa de su existencia y por cualquier motivo o situación adversa, sean reducidas a objetos(18).

La deliberación es el modo de tomar decisiones en un momento de incertidumbre, es la capacidad y actitud guiada de alumbrar la mejor solución ante un conjunto de valores. Este método es de gran utilidad, al dilucidar los problemas de origen y equilibrio de la vida que son objeto de reflexión $\operatorname{moral}(19)$.

La propuesta de la deliberación en cuestiones de bioética(20) fundamenta sus inicios en la edad antigua griega, con la finalidad principal de dar mayor consistencia a las decisiones humanas.

Deliberar es considerar atentamente el pro y el contra de los motivos de una decisión antes de adoptarla, y la razón o la sinrazón de los votos antes de emitirlos. La decisión -mediante el examen meditativo, reflexivo y ponderativo - tiene como fin el juicio que lleva a la acción. En el investigador es el pensar de carácter cognoscitivo de quien está a cargo del proyecto, con el objetivo de conocer el mayor número de posibilidades y tener la libertad de tomar la decisión prudente, ya que, al hablar de VIH y de SIDA en niños, tiene una proyección de responsabilidad individual, familiar, escolar e institucional, y su análisis va más allá del comportamiento biológico de la enfermedad; los factores sociales son importantes determinantes de la evolución de la enfermedad y el apego a las indicaciones médicas y de la adherencia al tratamiento en general.

Tabla 1. Método. Resumen de datos.

\begin{tabular}{|c|c|c|c|c|}
\hline Participantes & Edades & Diagnóstico & Atención & Cuidador Primario \\
\hline 6 niños y 5 niñas & Entre 2 y 13 años & $\begin{array}{l}\text { VIH y } \\
\text { adquiridos } \\
\text { transmisión vertical } \\
\text { (ocurrida durante el } \\
\text { embarazo, el parto o } \\
\text { por contacto con la } \\
\text { leche materna). }\end{array}$ & $\begin{array}{l}\text { Reciben atención } \\
\text { institucionalizada } \\
\text { de tipo federal para } \\
\text { el control de la } \\
\text { infección. }\end{array}$ & $\begin{array}{l}\text { De } 4 \text { niños y una niña: } \\
\text { la madre. } \\
\text { De uno de los niños; } \\
\text { ambos padres. } \\
\text { De un niño; abuela } \\
\text { materna. } \\
\text { De una niña; el } \\
\text { hermano. } \\
\text { De } 2 \text { niñas; la abuela } \\
\text { paterna. } \\
\text { De una niña; la Madre } \\
\text { adoptiva. }\end{array}$ \\
\hline
\end{tabular}




\section{Metodología}

Estudio de tipo cualitativo hermenéutico-deliberativo, con una muestra de niños tratados en el centro ambulatorio de prevención y atención en SIDA e ITS, Estado de México.

Se aplicó entrevistas que fueron grabadas a cuidadores primarios y niños. La persona a cargo institucionalmente de los nińos pudo tener acceso a la información en cualquier momento, atendiendo a las consideraciones éticas.

Se solicitó consentimiento y se dio aviso de confidencialidad a los tutores, y se informó a los niños mediante una carta de asentimiento.

\section{Resultados}

En la investigación participaron 11 niños entre 2 y 13 ańos y sus respectivos cuidadores primarios que no siempre fueron los padres, cuya causa más común fue el fallecimiento de uno de ellos o de ambos a causa del SIDA (tabla 1).

$\mathrm{Al}$ realizar la evaluación con base en las guías pediátricas(21) para determinación de la adherencia y poder ser corroborada con lo reportado en las narrativas, se encontró que 4 de los 11 participantes son adherentes (una niña y tres niños), y 7 no adherentes (cuatro niñas y tres niños), como puede observarse en la tabla 2. Cabe mencionar que estos datos simplemente son informativos y con el fin de ser un apoyo en la información obtenida de las entrevistas.

“...Tener el VIH no es fácil, pero dígame ¿Qué es fácil en ésta vida? ; $Y$ menos cuando pasan cosas que uno no se espera! (madre seropositiva de JMDL).

"... Lo que queda es cambiar la jugada, si se quiere seguir en el tablero" (padre seropositivo de AGAC).
La narrativa es mucho más que una historia que simplemente se cuenta, es en este caso la forma de externalizar las maneras de enfrentar, crear, figurar y configurar una situación que se tiene, que requiere de entendimiento y estrategias para seguir "en la jugada", como metafóricamente el paciente hace alusión a la vida. En este estudio se recurre a la narrativa porque la salud y la enfermedad no son meros hechos: incorporan valores. La enfermedad no puede ser concebida como un mero hecho biológico, es además un acontecimiento biográfico. Y por ello no puede ser comprendida sino desde los valores, que no son tratados por las ciencias sino por las humanidades.

\section{El respeto y la estima de sí}

La estima de sí es más esencial que el respeto de sí; el respeto de sí es el mismo aspecto de la estima de sí, solo que considerado bajo el régimen de la norma. En casos de difícil solución, motivados por el deber, la estima funge no solo como fuente sino como recurso del respeto, cuando ninguna norma puede ya ofrecer guía para el ejercicio del respeto. Por tanto, se puede decir que el respeto de sí constituye el paso indispensable para que surja la estima de sí, porque si me respeto a mí mismo y respeto a los otros, entonces, es posible que sea capaz de planear mis acciones y por ende alcanzar la estima de sí.

Para establecer la primacía de la ética sobre la moral, en su "tender hacia la vida buena", se pretende dilucidar lo que esto significa; con una ventaja, la de no tener que estudiar directamente el despliegue de la ipseidad (término ricoeuriano que hace alusión al desarrollo y ejercicio de una vida plena, aplicando la sabiduría práctica del humano) solo bajo la noción de la estima de sí.

“...Hay que enseñarles desde pequeños a quererse y a caminar solitos, y que se den a respetar, es lo que yo le digo a mi hijo" (madre seropositiva de JEL).

Tabla 2. Adherencia.

\begin{tabular}{|l|l|l|l|l|l|l|l|l|l|l|l|}
\hline & \multicolumn{1}{|l}{ Niños } & \multicolumn{3}{l|}{ Niñas } \\
\hline & AGAC & RRD & JSE & JMDL & RSC & JMC & AJCV & CLGM & YSR & LIC & MRR \\
\hline $\begin{array}{l}\text { Nivel de } \\
\text { adherencia }\end{array}$ & $75 \%$ & $100 \%$ & $95 \%$ & $90 \%$ & $65 \%$ & $95 \%$ & $85 \%$ & $95 \%$ & $90 \%$ & $55 \%$ & $80 \%$ \\
\hline
\end{tabular}


En la estructura de la narración la madre indica una recomendación al nińo como un inicio en el reconocimiento de su estima, y en la expresión "caminar solito" refiere el enfrentarse a las situaciones en las que ella no estará presente, pero además se deja abierta la posibilidad del "el otro" al que se pide respeto. Tal estructura dialógica implicada en el "con y para los demás" en "instituciones justas", además de la díada "yo-tú", comprende también al "cada uno" de todos los demás, cobijados por ese producto del vivir en comunidad, en primera instancia en el núcleo familiar, desde luego regida por la justicia(22).

“...Yo dije: pues si nos tocó vivir con este mal creo que no hay pa atrás, ya nos tocó y ni hablar, por mis hijos y por uno mismo tengo que seguir adelante hasta donde se pueda y hacer lo imposible por mantenernos estables, uno piensa que nunca le va a pasar esto pero si pasa y lo peor es que no sabemos nunca a quien le va a tocar, asi es la gente critica pero no ve que en una de esas también le puede tocar..." (madre seropositiva de AGAC).

La estima de sí se manifiesta en el entramado de la narración de sí mismo como síntesis de lo diverso, siendo el agente, el "yo puedo" de esta narración. La estima de sí supone una actitud para consigo mismo, para con los otros y una manera de estar en el mundo. Es una necesidad indispensable para la vida y para la realización de los planes de $\operatorname{vida}(23)$.

La estima de sí como horizonte de sentido posibilita narrar la vida desde un sí mismo que habla de un deseo, como deseo de felicidad, deseo de solidaridad y deseo de justicia, porque; "Apreciando nuestras acciones, nos apreciamos a nosotros mismos como el autor de las mismas" (22).

\section{Relaciones interpersonales plenas}

Una vez instaurado el estigma y dando como consecuencia actitudes discriminativas hacia los niños infectados por el VIH y sus cuidadores primarios, la siguiente cuestión a responder es si estas repercuten en la adherencia al tratamiento terapéutico, farmacológico, emocional y de cuidado de sí, retomando los principios de disponibilidad, convicción, compromiso y atestación de los cuidadores primarios, factores que se desarro- llan en las relaciones interpersonales plenas. Esto entendiendo que el menor aún no puede valerse totalmente por sí mismo y que existe en la infancia un aspecto de indefensión, y que, por lo tanto, quien está a cargo tiene la compleja tarea de comenzar con la estima de él mismo y el cuidado de sí para responder a estos aspectos.

"Lo recibió una doctora... me dijo: cómo es posible que se pongan a tener hijos si saben que tienen VIH, pero de una manera grosera, entonces, si me molesto porque como yo le dije ... si yo lo hubiera sabido, no lo tengo, no me expongo a que mi hijo hubiera nacido con el virus, yo no sabía, pero ya estamos aqui y lo que nos queda es enfrentar esta enfermedad o la que sea que nos toque, y lo que dijo la doctora si me molestó, porque lo dijo de una manera muy déspota, muy grosera" (madre seropositiva JEL).

La disponibilidad contiene dentro de su estructura la regla de reciprocidad, en la que el sí en pleno desarrollo es capaz de mantener su promesa y otorgarla en un acto de donación a la espera del otro capaz de exigir. Ricoeur dice: "la disponibilidad es ese éxodo que abre la conservación de sí a la estructura" (23).

Cuando la madre se asume responsable — en este caso habla de un "ya estamos aquî", refiriéndose a la nueva condición diferente-, abre ese vínculo de disponibilidad, tomando en cuenta esta máxima kantiana de tratar al otro como ella misma quisiera ser tratada, y legitimando esta promesa, dado el lazo consanguíneo y afectivo.

El compromiso y la convicción son los últimos peldaños en el difícil ascenso al reconocimiento de sí mismo. En la siguiente narrativa se presenta también el momento del compromiso y la convicción.

"Mi esposo falleció y asi fue como sospecharon que nosotros tenemos la infección y, cuando me entere, no lo creía, no lo creía... y no sé, más que nada por mi hija, sacar las fuerzas para seguir... cuando me dijeron de mi me senti mal, pero cuando me dijeron de mi hija me sentí peor, porque yo como quiera, pero ella va empezando a vivir y si ya acepté y venimos a las consultas, a los análisis; la verdad, aqui nos han apoyado para seguir adelante, nos han tratado bien y la familia de mi esposo también (madre seropositiva YSR). 
En la frase "no lo creía... y no sé, más que nada por mi hija sacar las fuerzas para seguir", el cuidador primario finalmente asume la convicción —que es la sabiduría en situación-, en la que se arriesga, a la que se somete, en la que se elige sobre la singularidad de la situación, y nos trae como consecuencia decir "no pudo ser de otro modo"(23). Por lo tanto, en la convicción: "Yo tomo posición, tomo partido, y así reconozco lo que, más grande que yo, más durable que yo, más digno que yo, me constituye en deudor insolvente" (24), la convicción se opone a la crisis, y permite encontrar el puesto en el universo que nos ha sido asignado, la injusticia y lo intolerable nos transforman de indolente y conformista, en "hombre de convicción que descubre creando y crea descubriendo" (25).

"Cuando una sabe que tiene el VIH y que su hijo también, todo cambia; me sentí más mal por lo mismo de que mi niño está enfermo, el miedo a que me discriminaran. Dije: si mi niño sigue así, quizá la gente lo sepa y lo empiece a rechazar. Pero ya ahorita que mejoró yo digo: no importa que estemos asi, que tengamos esa enfermedad, mientras el esté yo voy a luchar, sigo acercándome a Dios y siendo mejor persona, y ya me siento muy contenta porque lo veo bien..." (madre seropositiva RRD).

En la relación humana, con la solicitud y la responsabilidad se espera la acción correcta, como resultado del diálogo y la reciprocidad que se consigue en esa interacción. La relación humana no produce todos estos efectos en sí, sino en la me- dida en que vivimos en el ejercicio activo de las capacidades humanas; mientras se viva la relación humana de un modo mecánico, pasivo, habitual, no podrá alcanzarse esa ipseidad. Para efectuar unas relaciones interpersonales plenas, es preciso satisfacer exigencias dialogales que propone Paul Ricoeur como son: el respeto, la solicitud, la justicia, la amistad y, en un plano excepcional, la categoría supraética del amor(22).

\section{Ética e instituciones justas}

"En anhelo de una vida buena con y para el otro en instituciones justas" (22). Así Paul Ricoeur define ética en su obra Si mismo como otro, y procede a la explicación de cada parte que acuña el significado: la vida buena, la presencia del otro y, finalmente, en instituciones justas, y son precisamente estas últimas donde el hombre se desarrolla y lleva a cabo cada proceso vital y es posible la convivencia con los otros.

No existen relaciones interpersonales totalmente privadas, siempre se implica una tercera parte, otro u otros que intervienen en dicha relación. En esta noción del otro está implicado que el "vivir bien" incluya de alguna manera el sentido de justicia, y este es más extensa que el cara a cara.

En la explicación se encuentran en juego dos aserciones: la primera es que "vivir bien" no se limita a las relaciones interpersonales, sino que se extiende a la vida de las instituciones; la segunda, que la

La deliberación(26) se resume en el siguiente esquema.

\begin{tabular}{|c|c|c|}
\hline Deliberación sobre los hechos & Deliberación sobre los valores & Deliberación sobre los deberes \\
\hline $\begin{array}{l}\text { Diagnóstico de VIH y SIDA en } \\
\text { menores de } 15 \text { años, infectados } \\
\text { por transmisión vertical. } \\
\text { Acudir a una institución pública } \\
\text { para recibir tratamiento integral de } \\
\text { la enfermedad. } \\
\text { Estigma y discriminación que } \\
\text { los menores sufren a causa de su } \\
\text { estado serológico. } \\
\text { Tener adherencia al tratamiento o } \\
\text { no adherencia. }\end{array}$ & $\begin{array}{l}\text { Vínculo afectivo con el cuidador } \\
\text { primario que vela por el cuidado del } \\
\text { menor. } \\
\text { Estima hacia sí mismo. } \\
\text { Respeto de sí. } \\
\text { Cuidado de sí } \\
\text { El anhelo de una vida buena. } \\
\text { La salud. }\end{array}$ & $\begin{array}{l}\text { El apoyo de las instituciones sociales } \\
\text { públicas y privadas que brinden } \\
\text { servicio y atención integral (médica, } \\
\text { psicológica, odontológica, nutricional, } \\
\text { etc.). } \\
\text { Cuidar de los aspectos emocionales } \\
\text { del nińo como prioridad en el proceso } \\
\text { salud-enfermedad. } \\
\text { Informar con estrategias lúdicas } \\
\text { al niño sobre su enfermedad para } \\
\text { crear estrategias de afrontamiento } \\
\text { desde temprana edad y no agravar } \\
\text { la situación si se prolonga el } \\
\text { descubrimiento de su patología. }\end{array}$ \\
\hline
\end{tabular}


justicia presenta rasgos éticos no contenidos en la solicitud, a saber, esencialmente una exigencia de igualdad(23). Por lo tanto, la institución como punto de aplicación de la justicia, y la igualdad como contenido ético del sentido de la justicia son los retos de la investigación referida al tercer componente del objetivo ético ricoeuriano y al tercer momento de este trabajo.

"Pues lo que quiero consultar con el doctor y bueno que me den su opinión es que pienso venirme a la cuidad, ya sabe, allá en el pueblo no entenderían la enfermedad de mi niño y ya está en edad del kinder. Yo me muevo para acá, ya sea con el apoyo de la familia, ya veré, pero en las escuelas de aqui, en Toluca, no creo que haya problema de que tenemos el $V I H$. Necesita integrarse y que los maestros y niños lo acepten" (madre seropositiva de RRD).

La idea de institución se caracteriza fundamentalmente por costumbres comunes y no por reglas coaccionantes, dice Ricoeur. De este modo somos llevados al ethos. Y ello porque a la estructura constitutiva del hombre pertenece su inamisible condición social. Como individuo viviente y como animal racional el hombre es constitutivamente ente social, y como tal se realiza en todas sus actividades $(23,26)$.

\section{Discusión}

Aplicar el modelo hermenéutico-deliberativo a la bioética médica en el caso particular de los niños que viven con SIDA o con VIH, ha proporcionado un método para discutir posibles pautas de acción para fortalecer el apego al tratamiento de estos niños.

Pese a que la información acerca de la patología actualmente es mayor, en la práctica la discriminación hacia personas persiste, y puntualmente hacia los niños que padecen el síndrome, como evidencian los testimonios y lo comentado en algunos artículos de revisión y opinión(27-30).

Resultó importante para fines de esta investigación, observar el contenido social actual del paciente pediátrico y el manejo en cuanto a los tratamientos, así como el abordaje de la enfermedad. En el caso de México, se ha legislado a favor del tratamiento gratuito para pacientes con SIDA; sin embargo, es de suma importancia mencionar que el costo para la nación es muy elevado, por eso la inversión en prevención sigue aumentando. Como se observó en la información obtenida de las narraciones, dos de los niños entrevistados han fallado el primer esquema de tratamiento, esto implica un mayor costo al cambio de esquema y menos probabilidad de sobrevida, al reducir las oportunidades de cambiar fármacos en la terapia antirretroviral.

Los fármacos son eficaces si se toman sistemática y adecuadamente, según lo encontrado en este trabajo y mencionado en otros estudios(15). Sin embargo, la adherencia no consta solamente de la ingesta, sino de prácticas sanitarias, atención psicológica, odontológica y nutricional, entre otras cuestiones importantes (dados los resultados, se observó que sobre todo las emocionales). Por eso, la adherencia no sucede con frecuencia, por falta de recursos económicos, por las condiciones sociales y demográficas y por las patologías asociadas al SIDA que suelen complicar la evolución. Sin tomar en cuenta que aspectos como la estigmatización y discriminación que sufren los pacientes pueden llevarlos a un deterioro de las relaciones humanas y la pérdida del interés por la salud.

Dadas las condiciones sociopolíticas y económicas, la adherencia al tratamiento constituye actualmente una de las principales preocupaciones en relación al control del VIH y del SIDA asociadas al éxito o fracaso terapéutico. Es necesario relacionar el estigma y la discriminación producidas por el SIDA con el objetivo de proponer nuevos lineamientos de evaluación de la adherencia al tratamiento y de los factores asociados, que permitan diseñar intervenciones más eficaces.

El estigma y los actos discriminativos comienzan en el núcleo familiar y se disgregan en el resto de la familia, perpetuando dicho estigma. La forma en que se notó más esta situación en los niños fue que la información de su enfermedad se ocultó, haciendo aún más difícil el procedimiento de adherencia al tratamiento, teniendo por el contrario mayor desapego por la falta de conciencia de la enfermedad y generando rechazo a las indicaciones médicas en el momento de la noticia, que a menudo es en la adolescencia. 
En cuanto mayor sea el cuidado y la estima de sí mismo, mayor será el apego al tratamiento en las personas que por su condición de fragilidad o vulnerabilidad suelen tener más complicaciones de salud. Foucault, en una forma ética, pensaba que la vida se debería tomar como una obra de arte, como un proceso creativo de transformación individual: "Se trata de hacer de la propia vida una obra de arte, de liberarse del pegajoso contagio que secretan unas estructuras sociales en las que rige la ley del sálvese quien pueda"(31). El sujeto ético es aquel que pretende hacerse a sí mismo. Aquel que busca forjarse un sentido cautivador a su existencia.

Uno de los tópicos abordados por la filosofía de Ricoeur es la "identidad personal". Es a través del lenguaje como se adentra en el dominio de la narración; este ejercicio implica la pérdida del privilegio de la autoconciencia, desautorizando definitivamente la accesibilidad y la transparencia que habían distinguido al sujeto de modelo cartesiano (pienso, luego existo). Justamente por ello la importancia de la aplicación de la hermenéutica en temas de salud. Esto se presenta para el pensador francés como una filosofía reflexiva, que aborda el yo en un proceso — simbólico y textual- de compresión por el que se va construyendo(22).

Es necesario un proceso de discernimiento deliberativo para analizar la actitud que los médicos, profesores, familiares y sociedad en general deben tener hacia los niños con VIH/SIDA. Se ha mencionado ya en este y en otros estudios(32-34) que no es una enfermedad que tenga una connotación de culpabilidad, ya que adultos y menores tienen el mismo riesgo de contraerla.

Finalmente la deliberación sobre las decisiones finales pertenece a quién es responsable del caso: el paciente y su cuidador primario, y el personal de salud. Es importante asumir el papel de responsable en los diferentes contextos sociales.

Los cuidadores primarios son los responsables directamente de la situación del niño con VIH y SIDA, del apego al tratamiento y de las decisiones que se den en torno al tratamiento. Por tal motivo, es su deber decidir finalmente sobre los cursos de acción en cuanto a la toma de medicamentos, los cuidados y la revelación de la información.
Debe tomarse en cuenta la opinión de los niños, defendiendo su derecho a ser escuchados y a hacer valer su autonomía, evaluando en conjunto con el personal de salud la capacidad de decisión que el menor tiene sobre sus tratamientos.

En conclusión, se observó que el estigma asociado al VIH y al SIDA impide una discusión abierta tanto de sus causas como de sus posibles respuestas apropiadas. Esta discusión, así como la visibilidad y apertura respecto al SIDA, son requisitos previos para la movilización eficaz de gobiernos, comunidades y personas con el fin de responder a la epidemia. 
Referencias

1. Programa Conjunto de las Naciones Unidas sobre el VIH/SIDA. Situación de la epidemia de SIDA 2009; 36S: 7-63.

2. United Nations Program on HIV/AIDS. The Gap Report. UNAIDS; 2014. [Consultado:18 junio 2014] Disponible en: http://issuu.com/unaids/docs/20140716_unaids_gap_report/1?e=2251159/8627691

3. Centro Nacional para la Prevención y Control del VIH/SIDA. Vigilancia Epidemiológica de casos de VIH/SIDA en México. Registro Nacional de Casos de SIDA. 30 de junio del 2012.

4. Real SD. Discriminación y rechazo en la relación medico y paciente con VIH/SIDA.UAEM 2008: 3-25.

5. Franco S. SIDA y sociedad: crítica y desafíos sociales frente a la epidemia. Salud Pública de México 2012; 52: 199-200.

6. Goffman E. Stigma: notes on the management of a spoiled identity. Nueva York; 2000.

7. Aggleton P. Violación de los derechos humanos, estigma y discriminación relacionados con el VIH. ONUSIDA, ONU. 2005: 6-70.

8. Parker R. HIV and AIDS-related stigma and discrimination: a conceptual framework and implications for action. Social Science and Medicine 2003; 57: 13-24.

9. Programa Conjunto de las Naciones Unidas sobre el VIH/Sida. Reducir el estigma y la discriminación por el VIH: una parte fundamental de los programas nacionales del SIDA. Recurso para las partes interesadas en la respuesta al VIH en los diferentes paises. ONUSIDA; 2007.

10. United Nations Program on HIV/AIDS. Protocol for the identification of discrimination against people living with HIVUNAIDS. Geneva; 2000.

11. Lozano A. Concepciones culturales del VIH/Sida de estudiantes adolescentes. Revista Latinoamericana de Ciencias Sociales 2008; 6(2): 739-768.

12. Garzón R. Significado de las vivencias de niños y niñas afectados por el VIH/SIDA adscritos a un centro de atención y apoyo. Revista Colombiana de Enfermería 2012; 7(7): 86-98.

13. Fondo de las Naciones Unidas para la Infancia. Children and AIDS Third Stocktaking Report 2008. UNICEF, UNAIDS; 2008.

14. Fondo de las Naciones Unidas para la Infancia. Children and AIDS Country fact sheets. UNICEF, UNAIDS, WHO; 2007: 15-110.

15. Ruiz A. Adherencia al tratamiento en niñas y niños con VIH. Pensamiento Psicológico 2009; 5(12): 175-190.

16. Gordillo V. Sociodemographic and psychological variables influencing adherente to antiretroviral therapy. AIDS 2001; 13: 1763-1769.

17. Bautista J. En la asistencia a niños enfermos de SIDA. Humanidades Médicas JANO 2006; 1628.

18. Ricoeur P. Historia y Verdad. Madrid: Encuentro; 1990.

19. Gracia D. Fundamentos de bioética. Madrid: Eudema; 1989.

20. Gracia D. Como arqueros al blanco. San Sebastián: Triacastella; 2004: 197-224.

21. Infosida. Guidelines for the use of antiretroviral agents in pediatric HIV infection. December 2001. Disponible en http:// www.aidsinfo.nih.gov/guidelines

22. Ricoeur P. Si Mismo como otro. México; 2003.

23. Ricoeur P. Caminos del Reconocimiento, Madrid; 2005.

24. Ricoeur P. Historia y verdad, encuentro. Madrid; 1990.

25. Ricoeur P. Critica y convicción. Madrid: Síntesis; 2003.

26. Domingo T, Feito L. Bioética Narrativa, Madrid: Escolar y Mayo; 2013: 95-159.

27. Sarmiento PJ. Los problemas bioéticos de la epidemia del VIH/SIDA. Aproximación preliminar. Persona y Bioética 2002; 15: 7-26.

28. Gafo J, (ed.) El SIDA, un reto a la sanidad, la sociedad y la ética. Deberes éticos de la medicina actual. Madrid: Universidad Pontificia Comillas; 1989.

29. Júdez J, Barbero J, García D. Ética en el paciente VIH. $4^{\circ}$ Seminario de Atención Farmacéutica. Madrid; 2009.

30. Bautista J. En la asistencia a niños enfermos de SIDA. Humanidades Médicas 2006.

31. Foucault M. Tecnologías del yo. Barcelona: Paidós; 1990.

32. Garcia P, Kalish L, Pitt J, et al. Maternal Levels of Plasma Human Immunodeficiency Virus Type 1 RNA and the Risk of Perinatal Transmission. N Engl J Med 1999; 341: 394-402.

33. Gretchen R, Wheeler G, Tucker N, et al. Nonadherence With Pediatric Human Immunodeficiency Virus Therapy as Medical Neglect. Pediatrics USA 2004; 114(3): 346-353. 
Estigma, discriminación y adherencia al tratamiento en niños con VIH y SIDA - Paola Conde Higuera et al.

34. Ballester R, Campos A, García S, et al. Variables moduladoras de la adherencia al tratamiento en pacientes con infección por VIH. Psicologia Conductual 2011; 9: 299-322.

Recibido: 30 de septiembre de 2014

Aceptado: 3 de diciembre de 2014 